\title{
COMUNICAÇÃO
}

\author{
MUISEU CEROPLÁSTICO \\ AUGUSTO ESTEVES (1891-1966)
}

\section{Carlos da Silva Lacaz}

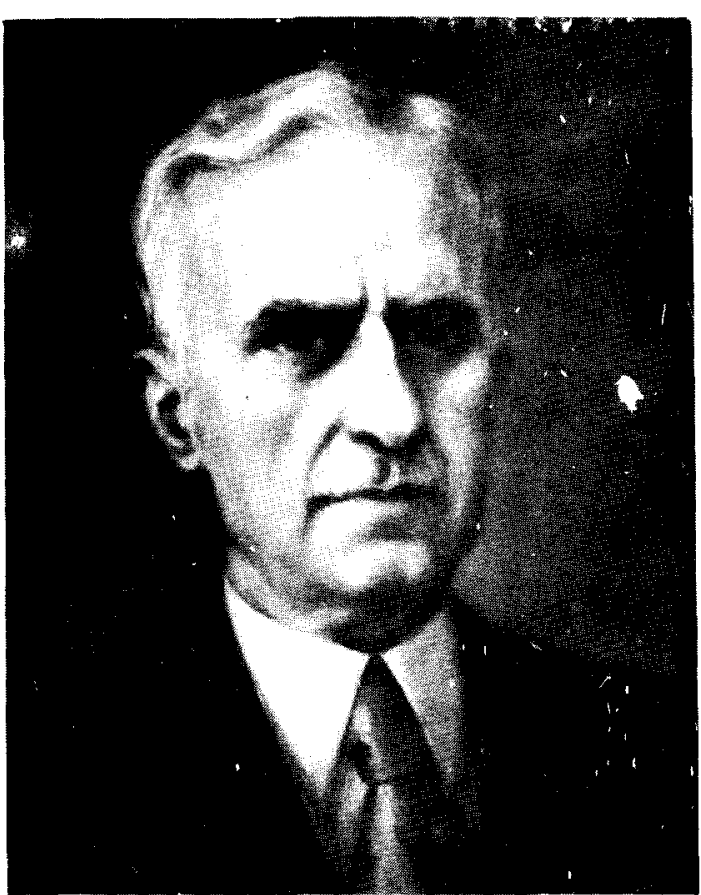

A Faculdade de Medicina da Universidade de São Paulo guarda em seu prádio central, à Avenida Dr. Arnaldo 455 uma preciosidade artística - o Museu Ceroplástico August, Esteves (1891-1966) trabalho de um homem notável, modesto c bom, paranaense ilustre, naiura! de Sào José da Boa Vista, lá nascido a 16 de oui ro ro 1891 . Iluminado pela centelha divina, Esteves, antigo Auxiliartécnico da Clínica Dermatológica da Faculdade de Medicina, de 1943 a 1959, a pedido do saudoso e eminente Prof. João de Aguiar Pupo, começou a se dedicar à ceroplastia, fazendo centenas de peças de cera representando principalmente as dermatoses que ocorrem em nosso meio. Desenhista e retratista de raros predicados, o eminente artista brasileiro

Professor emérito da Faculdade de Medicina da Universidade de São Paulo, São Paulo, SP.

Recebido para publicação em 11/05/93 já havia nos legado dezenas de quadros representando os prédios da Rua Brigadeiro Tobias, onde se localizavam, inicialmente, os laboratórios da nossa Escola, fundada em altos padröes de honestidade científica pelo Conselheiro Francisco de Paula Rodrigues Alves, então presidente do Estado, a 12 de dezembro de 1912. Retratos de alguns antigos professores da Faculdade de Medicina foram, também, por ele executados, de maneira primorosa.

A 12 de maio de 1980, ainda vivo o Prof. João de Aguiar Pupo, titular de Clínica Dermatológica da Faculdade de Medicina e seu antigo Diretor, tivemos o privilégio de implantar em um dos saguões do Departamento de Microbiologia e Imunologia da Faculdade de Medicina, hoje esquartejada pelos aríetes da demolição, bem como pelos Catões do ensino médico, o "Museu Ceroplástico Augusto Esteves", iniciativa que se deve, também, à valiosa colaboração recebida do Prof. Sebastião de Almeida Prado Sampaio, bem como de Waldomiro Siqueira Junior, e Dante Nese, auxiliados por Jayme Ferreira, Roberto de Souza e Almir Robson Ferreira.

O acervo deste Museu é representado por 259 peças cuidadosamente elaboradas pelo genial e humilde servidor da Casa de Arnaldo. Escrevemos pequeno folheto, cuja publicação se deve a Heitor Osuraldo Dupont, contendo breve biografia do renomado artista que tanto serviu à Faculdade de Medicina. Trata-se de um roteiro que serve de orientação àqueles que visitam o Museu, talvez o único no mundo, em número de peças e qualidade de confeç̧ão.

Os Laboratórios Schering-Plough, sentindo a importância e a grandeza desta obra decidiram realizar um vídeo deste Museu, com a nossa colaboração e a do Prof. José Eduardo Costa Martins, atual presidente da Sociedade Brasileira de Dermatologia. Foi uma obra patriótica, pois o referido vídeo, de excelente qualidade técnica, vem sendo passado em vários céntros médicos do país, enaltecendo o trabalho de um artista brasileiro, cuja vida deve servir de exemplo aos moços de nossa terra. 
Comunicação. Lacaz CS. Museu ceroplástico Augusto Esteves (1891-1966). Revista da Sociedade Brasileira de Medicina Tropical 26:125-126, abr-jun, 1993.

Augusto Esteves começou a trabalhar no Instituto Butantã, ilustrando trabalhos de Ofidiologia de Vital Brazil. Casou-se, depois, com umas das filhas do renomado cientista brasileiro, uma de nossas glórias científicas.

Em 1936, iniciou suas atividades na velha Santa Casa de Misericórdia de São Paulo, em modesta sala que o Prof. Aguiar Pupo lhe havia conseguido. No Instituto Oscar Freire deixou, também, os sinais de sua operosidade. Amigo de Flamínio Fávero - ambos eram protestantes, homens de fé e de ilibado caráter, trabalhou, também, no Instituto Oscar Freire, bem como no antigo "Instituto Pinheiros".

No Instituto de Medicina Tropical de São Paulo existiam várias peças de cera de Augusto Esteves, mas lamentavelmente alguns aríetes da demolição acabaram por desativar o Museu que lá implantei em 1959, por ocasião da fundação daquele Centro de Tropicologia Médica.

O Museu Ceroplástico Augusto Esteves é composto de 31 paredes de lambril de fórmica distribuídas em labirinto, numerados, contendo, conforme referimos, 259 peças dermatológicas.

Faleceu o queridíssimo amigo e renomado artista a 4 de fevereiro de 1966, na cidade de São Paulo, saindo seu corpo do salão nobre do Instituto Oscar Freire para o cemitério do Redentor. A oração fúnebre pronunciou-a o Prof. João de Aguiar Pupo.

A terra paulista recolheu o corpo de um grande brasileiro, cuja memória estará sempre vivíssima no coração de seus amigos e familiares e numa perene recordação de todos aqueles que com ele conviveram. Conhecemos Augusto Esteves no Hospital das Clínicas da Faculdade de Medicina, quando ele modelava peças de cera representando lesões dermatológicas próprias da nosologia tropical e, com ele, realizamos modesto trabalho sobre a profilaxia do emboloramento, freqüente nas caixas que continham tão valioso material iconográfico. Modesto, resignado, desambicioso de honrarias, idealista, foi exemplar chefe de família, um homem de bem, mantendo-se sempre fiel a seus princípios e aos seus ideais.

Augusto Esteves, o amigo que desapareceu, estará sempre presente entre nós, porque quem viveu para os outros pode também reviver na gratidão e na lembrança de seus semelhantes.

A Faculdade de Medicina orgulha-se de ter muitos anos de sua vida ligados ao nome e à ação benemérita deste grande brasileiro. Ele não tem ruas ou praças com o seu nome, mas sua obra será perene, feita de ricas benemerências que lhe conferem valor eterno. 